ORIGINAL ARTICLE

\title{
Hepatic myospherulosis complicating portal vein embolisation
}

\author{
P C W Lui, I S C Luk, C K L Lee, Y H Lui, C Y Leung, C H Choi
}

J Clin Pathol 2004;57:155-158. doi: 10.1136/jcp.2003.11965

See end of article for authors' affiliations

.....................

Correspondence to:

Dr P C W Lui, Department

of Pathology, United

Christian Hospital, 130

Hip Wo Street, Kwun

Tong, Hong Kong;

luicwphilip@hotmail.com

Accepted for publication 29 August 2003 Aims: Myospherulosis is a rare condition characterised by sac-like structures containing spheroid bodies in
cysts or cystic spaces in the tissue. This condition has not previously been reported in the liver. The association with previous portal vein embolisation using a mixture of butyl 2-cyanoacrylate and ethiodised oil and the proposed mechanism of pathogenesis are discussed.

Methods: Samples from 8 patients treated by hepatectomy after portal vein embolisation using a mixture of butyl 2-cyanoacrylate and ethiodised oil were retrieved from the archives of the United Christian Hospital, Hong Kong. The histological specimens were reviewed. A panel of histochemical and immunohistochemical stains was used.

Results: All cases showed hepatic myospherulosis within the veins. The veins were denuded of endothelium, which was replaced by granulation tissue and fibrous tissue with a lymphoplasmacytic infiltrate. Foreign body-type giant cells (six cases) and eosinophilic infiltrates (seven cases) were noted in most cases. Both parent bodies and endobodies were stained red by Papanicolaou and Masson's trichrome and stained blue by solochrome cyanine. The endobodies showed immunoreactivity towards glycophorin A. They were negative for Alcian blue, periodic acid Schiff, Grocott, and Ziehl-Neelsen stains. Conclusions: The endobodies of myospherulosis may be misdiagnosed as fungi or algae by the unwary. The clinical history, intravascular location, lack of staining with periodic acid Schiff and Grocott stains, and positive glycophorin A staining are generally sufficient for a confident diagnosis of myospherulosis.
M yospherulosis is characterised by microscopic sac-like structures containing spheroid bodies in the tissue. It is infrequently reported in the literature, and its nature was a matter of debate until its pathogenesis was confirmed to be the alteration of red cells by lipid material.

"Portal vein embolisation results in a significantly greater increase in liver volume and a shorter hospital stay than is seen in patients treated by portal vein ligation"

Portal vein embolisation (PVE) is a safe method that is used to increase the functional liver remnant volume and achieve resectability for bulky liver tumours. It is usually indicated when the future liver remnant (FLR) volume is estimated to be too small for major liver resection. A previous study has shown that the hypertrophy of the FLR induced by PVE in patients with chronic liver disease significantly decreased the rate of postoperative complications. ${ }^{1}$ In addition, PVE results in a significantly greater increase in liver volume and a shorter hospital stay than is seen in patients treated by portal vein ligation. ${ }^{2}$

To the best of our knowledge, this is the first reported study of myospherulosis in the liver associated with PVE.

\section{METHODS}

A total of eight cases of hepatectomy after PVE were retrieved from the archives of the United Christian Hospital, Hong Kong over a period of two years. Clinical data and follow up information were obtained from the medical files. The histological materials were reviewed, and representative areas were selected for histochemical staining (Papanicolaou, Masson's trichrome, Alcian blue, periodic acid Schiff, Grocott, Ziehl-Neelsen, and solochrome cyanine) and immunohistochemical staining for red blood cells (glycophorin A; monoclonal antibody JC159; dilution 1/30; Dakopatts, Glostrup, Denmark).

\section{RESULTS}

\section{Clinical features}

Table 1 summarises the clinical features of the patients. There were seven male patients and one female patient. They ranged from 48 to 72 years in age (mean, 63.6). Hepatectomy was performed for cholangiocarcinoma $(\mathrm{n}=3)$, adenocarcinoma of the gall bladder $(n=1)$, hepatocellular carcinoma $(\mathrm{n}=1)$, metastatic colonic adenocarcinoma $(\mathrm{n}=2)$, and one case of suspected cholangiocarcinoma $(n=1)$. Tumour was confirmed in the resected specimens except in case 4 (table 1). The tumour size ranged from $2 \mathrm{~cm}$ to $8 \mathrm{~cm}$ in greatest dimension (mean, 4.47). Portal vein thrombosis was noted on macroscopic examination in four cases (cases 4, 5, 7, and 8). The time interval between PVE and hepatectomy ranged from 15 days to 32 days. All patients were alive for a follow up period ranging from two to 21 months (mean, 8.6).

\section{Histological features}

Histological examination showed cholangiocarcinoma (cases 1, 5, and 7), hepatocellular carcinoma (case 2), poorly differentiated adenocarcinoma of the gall bladder (case 3), and metastatic colonic adenocarcinoma (cases 6 and 8). No tumour was found in case 4 . In addition, there were several light brown, irregular shaped saccular structures (parent bodies) enclosing small spherules (endobodies) within the portal veins in all eight cases (fig 1). These veins were denuded of endothelium, and replaced by granulation tissue and fibrous tissue with a lymphoplasmacytic infiltrate (fig 2).

Abbreviations: FLR, future liver remnant; PVE, portal vein embolisation 
Table 1 Clinicopathological features of the eight patients treated with portal vein embolisation

\begin{tabular}{|c|c|c|c|c|c|c|}
\hline Case & Sex/age & Diagnosis & Tumour size $(\mathrm{cm})$ & PVT (gross) & $\begin{array}{l}\text { Interval between PVE and } \\
\text { hepatectomy (days) }\end{array}$ & Follow up (months) \\
\hline 1 & $M / 66$ & Cholangiocarcinoma & $2.8 \times 2 \times 2$ & No & 15 & 21 \\
\hline 2 & $\mathrm{~F} / 72$ & Hepatocellular carcinoma & $8 \times 8 \times 5$ & No & 21 & 16 \\
\hline 3 & $M / 69$ & $\begin{array}{l}\text { Poorly differentiated adenocarcinoma of } \\
\text { gall bladder }\end{array}$ & $7.5 \times 7 \times 7$ & No & 21 & 8 \\
\hline 4 & $M / 48$ & $\begin{array}{l}\text { Suspected cholangiocarcinoma. No } \\
\text { malignancy on resection }\end{array}$ & & Yes & 21 & 8 \\
\hline 5 & $M / 72$ & Cholangiocarcinoma & $2.5 \times 2.5 \times 2$ & Yes & 28 & 6 \\
\hline 6 & $M / 56$ & Metastatic colonic adenocarcinoma & $5.5 \times 4 \times 3.5$ & No & 22 & 4 \\
\hline 7 & $M / 56$ & Cholangiocarcinoma & 2 & Yes & 32 & 4 \\
\hline 8 & $M / 70$ & Metastatic colonic adenocarcinoma & $3 \times 2.5 \times 2.5$ & Yes & 18 & 2 \\
\hline
\end{tabular}

Foreign body-type giant cells (six cases; fig 3) and eosinophilic infiltrates (seven cases; fig 2) were noted in most cases. Both parent bodies and endobodies were stained red by Papanicolaou and Masson's trichrome, stained blue by solochrome cyanine, and were negative for Alcian blue, periodic acid Schiff, Grocott, and Ziehl-Neelsen stains. The endobodies showed immunoreactivity towards glycophorin A (fig 4). The overall features were those of myospherulosis.

\section{DISCUSSION}

McClatchie et al in 1969 first described seven African patients with myospherulosis in skeletal muscle. ${ }^{3}$ It is an uncommon condition characterised by the presence of numerous cystic spaces containing spheroid bodies on histological examination. This entity is called myospherulosis because such spheroid bodies have been mistaken as fungi. Since the original description, myospherulosis has been reported in different parts of the body, including the paranasal sinus, ${ }^{4-6}$ eye, ${ }^{7}$ brain, ${ }^{8}$ dermis, ${ }^{9}$ breast, ${ }^{10}$ and renal adipose tissue. ${ }^{11}$ Some forms are related to tumours, such as steatocystoma, ${ }^{12}$ benign cystic teratoma, ${ }^{13}$ and renal cell carcinoma. ${ }^{14}$ The origin of myospherulosis has been studied extensively, and it has been suggested to result from the alteration of red blood cells ${ }^{415}{ }^{16}$ and macrophages. ${ }^{17}$ The morphology, histochemical properties, and immunohistochemical profiles of the endobodies strongly suggest that they represent altered red blood cells. The parent bodies may be formed by the fusion of red blood cell membranes. Rosai ${ }^{4}$ confirmed the origin of

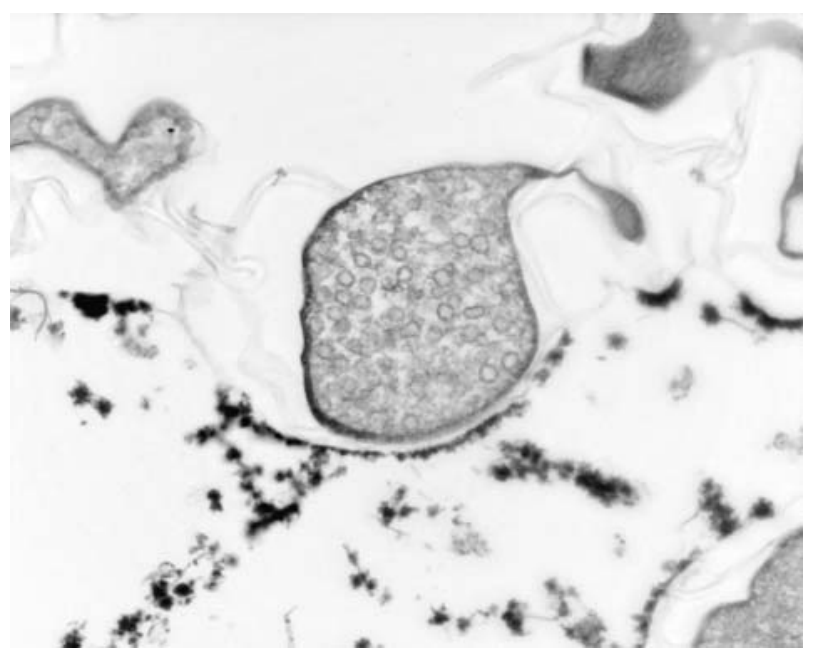

Figure 1 High magnification photomicrograph showing aggregates of altered red cells (endobodies) surrounded by a thin membrane (parent bodies) (original magnification, $\times 40$; haematoxylin and eosin stain).

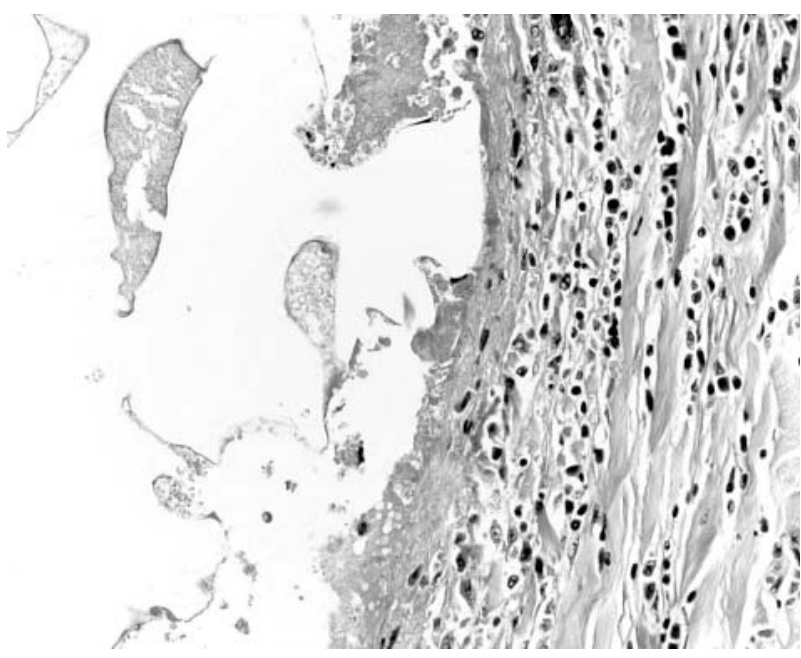

Figure 2 Photomicrograph showing a denuded vein with lymphocytic and eosinophilic infiltrates. Spheroid bodies are encysted within small spaces in the vascular lumen (haematoxylin and eosin stain).

myospherulosis to be altered red cells by the experimental production of these spheroids by the action of tetracycline ointment on a pure preparation of human erythrocytes. Wheeler et al demonstrated the production of myospherules using either lanolin or petrolatum in vitro. ${ }^{16}$ Kakizaki and

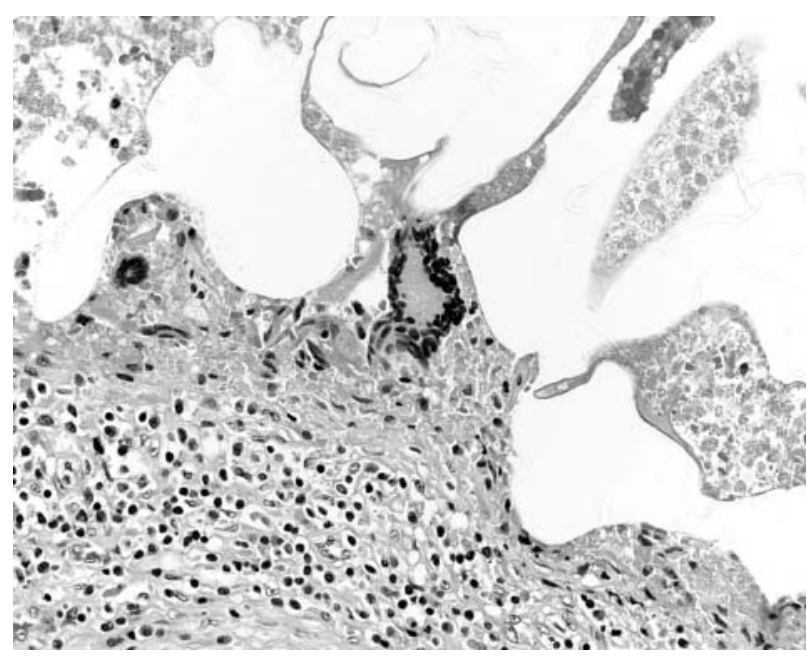

Figure 3 Photomicrograph showing foreign body-type giant cells in the denuded vein (haematoxylin and eosin stain). 


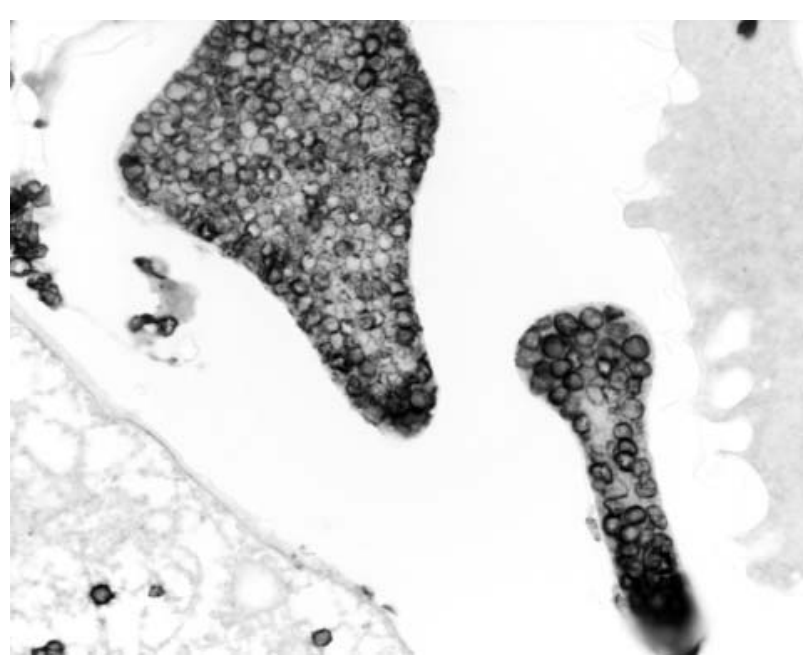

Figure 4 Photomicrograph showing positive immunoreactivity towards glycophorin A.

Shimada ${ }^{15}$ showed that the parent body of myospherulosis was formed as a result of the physical emulsion phenomenon between lipid containing materials and blood. The parent body membrane was composed of the contents exuded from the altered red blood cells. The endobody comprises degenerate red blood cells with diameters of 5-7 $\mu \mathrm{m}$, and was formed as a result of cell membrane pore formation during the process of red blood cell degeneration. Myospherulosis can be categorised as iatrogenic or endogenous, according to the origin of the lipid containing material. The iatrogenic type is usually caused by petroleum based material in therapeutic agents, such as oil based haemostatic packings, and the endogenous type is related to endogenous lipids, such as clear cell type renal cell carcinoma with a high lipid content. ${ }^{14}$

A mixture of butyl 2-cyanoacrylate (Histoacryl) and ethiodised oil (lipiodol) is used for portal vein embolisation in our centre. Butyl 2-cyanoacrylate is a cyanoacrylate adhesive. Cyanoacrylate compounds are used as surgical tissue adhesives or sclerosing agents. They are used as tubal occlusive agents for female sterilisation, for sclerotherapy in bleeding gastric varices, and for the embolisation of vascular lesions. Because cyanoacrylate compounds are radiolucent, they have to be used in conjunction with a radiopaque contrast material, such as ethiodised oil, for the visualisation and guidance of intravascular injections. Ethiodised oil is slowly metabolised to fatty acid and inorganic iodine. In one study, the mean biological half life of ethiodised oil I-131 ranged from 5.2 to 12.6 days. ${ }^{18}$

It appears that the metabolism of ethiodised oil into inorganic iodine and fatty acid plays a major role in the pathogenesis of myospherulosis in the liver. The administration of a mixture of butyl 2-cyanoacrylate and ethiodised oil into the portal vein causes thrombosis of the vessel (cyanoacrylate effect), resulting in the entrapment of red blood cells in an area of high concentration of ethiodised oil. Because the ethiodised oil is slowly metabolised into inorganic iodine and fatty acid, the prolonged contact between the fatty acid and the red blood cells results in the alteration and degeneration of the red blood cells to form parent bodies and endobodies in typical myospherulosis.

"It appears that the metabolism of ethiodised oil into inorganic iodine and fatty acid plays a major role in the pathogenesis of myospherulosis in the liver"

\section{Take home messages}

- Hepatic myospherulosis is an under-recognised condition and should be considered if "spherules" are noted microscopically, in the context of portal vein thrombosis with ethiodised oil as contrast agent

- The endobodies of myospherulosis may be misdiagnosed as fungi or algae but the clinical history, intravascular location, lack of staining with periodic acid Schiff and Grocott stains, and positive glycophorin A staining should point towards a diagnosis of myospherulosis

In these cases, the proposed mechanism mainly depends on two elements: the high concentration of the ethiodised oil and the time taken for its degradation. In our eight patients, the concentration of the chemical was kept constant and there were at least 15 days, more than one half life of the ethiodised oil, for such degradation to occur. It is reasonable to assume that the alteration and degeneration of the red blood cells might not occur if the time lapse between the embolisation procedure and hepatectomy were too short.

In our present study, there was no association between the tumour type and myospherulosis, as demonstrated by the consistent occurrence of myospherulosis in different kinds of tumours in the resected livers. Moreover, the presence of myospherulosis in the patient without tumour (case 4, table 1) confirms that the presence of tumour is not a prerequisite for the occurrence of myospherulosis.

The endobodies may be misdiagnosed as fungi or algae, such as coccidioidomycosis or Prototheca, by the unwary. However, the clinical history, intravascular location, lack of staining with periodic acid Schiff and Grocott stains, and positive glycophorin A staining are generally sufficient to distinguish myospherulosis from fungi and algae.

In summary, hepatic myospherulosis is an under-recognised condition and should be considered if "spherules" are noted microscopically, in the context of portal vein thrombosis with ethiodised oil as contrast agent.

\section{Authors' affiliations}

P C W Lui, I S C Luk, C K L Lee, Y H Lui, C Y Leung, C H Choi, Department of Pathology, United Christian Hospital, 130 Hip Wo Street, Kwun Tong, Hong Kong

\section{REFERENCES}

1 Farges O, Belghiti J, Kianmanesh R, et al. Portal vein embolization before right hepatectomy: prospective clinical trial. Ann Surg 2003;237:208-17.

2 Broering DC, Hillert C, Krupski G, et al. Portal vein embolization vs. portal vein ligation for induction of hypertrophy of the future liver remnant. J Gastrointest Surg 2002;6:905-13.

3 McClatchie S, Warambo MW, Bremmer AD. Myospherulosis: a previously unreported disease? Am J Clin Pathol 1969;51:699-704

4 Rosai J. The nature of myospherulosis of the upper respiratory tract. Am J Clin Pathol 1978;69:475-81.

5 Travis WD, Li CY, Wieland LH. Immunostaining for hemoglobin in two cases of myospherulosis. Arch Pathol Lab Med 1986;1 10:763-5.

6 Wheeler TM, Sessions R, McGavran MH. Myospherulosis: a preventable iatrogenic nasal and paranasal entity. Arch Otolaryngol 1980;106:272-4

7 Kini U, Babu MK. Ocular spherulocytosis. J Clin Pathol 1996;49:857-8.

8 Mills SE, Lininger JR. Intracranial myospherulosis. Hum Pathol 1982;13:596-7.

9 Lazarov A, Avinoach I, Giryes H, et al. Dermal spherulosis (myospherulosis) after topical treatment for psoriasis. J Am Acad Dermatol 1994;30:265-7.

10 Shabb N, Sneige N, Dekmezian RH. Myospherulosis. Fine needle aspiration cytologic findings in 19 cases. Acta Cytol 1991;35:225-8.

11 Le Gall F, Huerre M, Cipolla B, et al. A case of myospherulosis occurring in the perirenal adipose tissue. Pathol Res Pract 1996;192:172-8. 
12 Patterson JW Kannon GA. Spherulocystic disease ("myospherulosis") arising in a lesion of steatocystoma multiplex. J Am Acad Dermatol 1998; $38: 274-5$.

13 Vuong PN. Spontaneous myospherulosis developing at contact with a mature cystic dysembryoma of the ovary: pathogenetic discussion apropos of a case diagnosed by aparoscopic biopsy. J Gynecol Obstet Biol Reprod (Paris) 1998;17:15-18.

14 Chau KY, Pretorius JM, Stewart AW. Myospherulosis in renal cell carcinoma. Arch Pathol Lab Med 2000;124:1476-9.
15 Kakizaki H, Shimada K. Experimental study of the cause of myospherulosis. Am J Clin Pathol 1993;99:249-56.

16 Wheeler TM, McGravran MH. Myospherulosis: further observation. Am J Clin Pathol 1980:73:685-6.

17 Rose AG, Timme AH, Price SK, et al. Myospherulosis: further ultrastructural observations. Histopathology 1979;3:421-32.

18 Fallat RJ, Powell MR, Youker JE, et al. Pulmonary deposition and clearance of 131--labeled oil after lymphography in man. Correlation with lung function. Radiology 1970;97:51 1-20. 